\title{
Highway Stopping Sight Distance, Decision Sight Distance, and Passing Sight Distance Based on AASHTO Models
}

\author{
Azad Abdulhafedh \\ University of Missouri-Columbia, Missouri, USA \\ Email: asa8cd@mail.missouri.edu
}

How to cite this paper: Abdulhafedh, A. (2020) Highway Stopping Sight Distance, Decision Sight Distance, and Passing Sight Distance Based on AASHTO Models. Open Access Library Journal, 7: e6095. https://doi.org/10.4236/oalib.1106095

Received: January 21, 2020

Accepted: March 20, 2020

Published: March 23, 2020

Copyright () 2020 by author(s) and Open Access Library Inc.

This work is licensed under the Creative Commons Attribution International License (CC BY 4.0).

http://creativecommons.org/licenses/by/4.0/

\section{(c) (i) Open Access}

\begin{abstract}
Highway sight distance is a measure of roadway visibility, which is an important factor in the assessment of road safety. Greater visibility can provide motorists more time to avoid crashes and conflicts, facilitating safe and efficient operation. However, poor visibility can reduce the driver's ability to react to changing conditions and is a significant factor in roadway crashes and near collisions. A driver's ability to view ambient roadway conditions is necessary for safe operation of a vehicle. The roadway must have sufficient sight distance that drivers have the time to react to and avoid striking unexpected objects in their path. In addition, certain two-lane, two-way highways should also have adequate passing sight distance to enable drivers to use the opposing traffic lane for passing other vehicles without interfering with oncoming vehicles. This paper presents the concept and analysis of three different types of sight distance that are considered in highway geometric design based on AASHTO models: 1) the sight distances needed for stopping, applicable to all highway travels; 2) the sight distances needed for decisions at hazardous complex locations; and 3) the passing sight distance needed on two lane highways.
\end{abstract}

\section{Subject Areas}

Civil Engineering, Geometry, Operational Research, Topology

\section{Keywords}

Stopping Sight Distance, Decision Sight Distance, Passing Sight Distance, Highway Geometric Design

\section{Introduction}

According to the American Association of State Highway and Transportation 
Officials (AASHTO), the ability of a driver to see ahead on the roadway is very important for the efficient operation of a vehicle. In general, sight distance is the length of roadway ahead that is visible to the driver [1] [2] [3]. Moreover, the minimum sight distance at any point on the roadway should be long enough to enable a vehicle traveling at or near the design speed to stop before reaching a stationary object in its path. Although greater length is desirable, sight distance at every point along the highway should be at least that required for a below average driver or vehicle to stop in this distance. Providing adequate sight distance on a roadway is one of the central tasks of the highway designer. Adequate sight distance provides motorists the opportunity to avoid obstacles on the roadway, to merge smoothly with other traffic, and to traverse intersections safely. Ramp, interchange, and intersection designs are typically completed in tightly constrained spaces with many structural, earthwork, and roadway elements present that may obstruct sight distance. If consideration to sight distance constraints is not given early in the design process, roadway design may be compromised and may reduce the level of safety on the completed roadway. Therefore, sight distance criteria must be presented in a clear and comprehensive manner to facilitate the completion of satisfactory roadway design. Sight distance criteria have impact on virtually all elements of highway design and many elements of the traffic operation, and control. The roadway geometric design features, the presence of obstacles at the roadsides and the pavement surface condition are fixed by sight distance requirements. The nature of traffic controls, their placement and their effects on traffic stream conditions, such as traffic queues, must take account of sight distance requirements. Roadway sight distance can be categorized into four types according to AASHTO Green Book [1] [2] [3]: 1) stopping sight distance; 2) decision sight distance; 3) passing sight distance; and 4) intersection sight distance. Each of these sight distances accounts for the reaction time of the driver and the subsequent time required to complete the associated stopping task. This paper presents the concept and analysis of the first three types of sight distance based on AASHTO models: 1) the sight distances needed for stopping, applicable to all highway travels; 2) the sight distances needed for decisions at hazardous complex locations; and 3) the passing sight distance needed on two lane highways.

\section{Stopping Sight Distance}

Stopping sight distance (SSD) reflects a distance within which a driver can effectively see an object in the roadway and stop their vehicle before colliding with the object [1] [2] [3]. The available sight distance on a roadway should be long enough to enable a vehicle traveling at or near the design speed to stop before reaching a stationary object in its path. Although greater lengths of visible roadway are desirable, the sight distance at every point along a roadway should be at least that needed for a below-average driver or vehicle to stop. Recommended protocols for calculating stopping sight distances account for the basic principles of physics and the relationships between various design's parameters. Stopping 
sight distance can be determined as the sum of two distances, namely: 1) Reaction distance (the distance a vehicle travels from the moment a driver sees the object until the driver applies the brakes) and; 2) Braking distance (the distance a vehicle travels from the moment the brakes are applied until the vehicle comes to a complete stop). The following equation shows how SSD is typically computed by combining these two distances [1] [2]:

$$
S S D=0.278 V T+0.039 V^{2} / a
$$

where:

$S S D=$ stopping sight distance, $\mathrm{m}$;

$V=$ highway design speed, $\mathrm{km} / \mathrm{h}$;

$T=$ brake reaction time, seconds;

$a=$ deceleration rate, $\mathrm{m} / \mathrm{s}^{2}$.

AASHTO Greenbook (2018 and 2011) recommends a (2.5 seconds) as the driver's reaction time, and $\left(3.4 \mathrm{~m} / \mathrm{s}^{2}\right)$ as the deceleration rate for stopping sight distance calculations. Figure 1 provides an illustration of the factors contributing to the AASHTO recommendations on SSD. Table 1 shows the SSD on level

Table 1. AASHTO Stopping sight distance on level roadways.

\begin{tabular}{ccccc}
\hline $\begin{array}{c}\text { Design Speed } \\
(\mathrm{km} / \mathrm{h})\end{array}$ & $\begin{array}{c}\text { Reaction Distance } \\
(\mathrm{m})\end{array}$ & $\begin{array}{c}\text { Braking Distance } \\
(\mathrm{m})\end{array}$ & Calculated SSD $(\mathrm{m})$ & Design SSD $(\mathrm{m})$ \\
\hline 20 & 13.9 & 4.6 & 18.5 & 20 \\
30 & 20.9 & 10.3 & 31.2 & 35 \\
40 & 27.8 & 18.4 & 46.2 & 50 \\
50 & 34.8 & 28.7 & 63.5 & 65 \\
60 & 41.7 & 41.3 & 83.0 & 85 \\
70 & 48.7 & 56.2 & 104.9 & 105 \\
80 & 55.6 & 73.4 & 129.0 & 130 \\
90 & 62.6 & 92.9 & 155.5 & 160 \\
100 & 69.5 & 114.7 & 184.2 & 185 \\
110 & 76.5 & 138.8 & 215.3 & 220 \\
120 & 83.4 & 165.2 & 248.6 & 250 \\
130 & 90.4 & 193.8 & 284.2 & 285 \\
\hline
\end{tabular}

AASHTO (2011) STOPPING SIGHT DISTANCE (SSD)

SSD $=$ Reaction Distance + Braking Distance

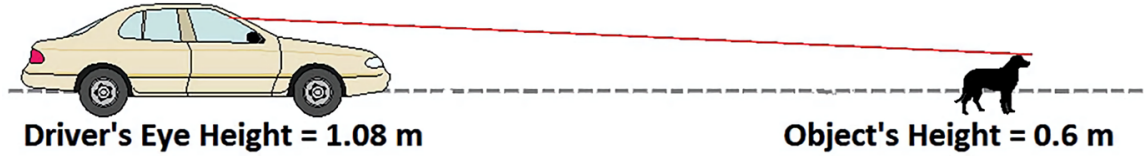

Figure 1. AASHTO criteria for stopping sight distance. 
terrains. The recommended height of the driver's eye above the road surface is $(1.08 \mathrm{~m})$ and the height of an object above the roadway is $(0.6 \mathrm{~m})$.

\subsection{Driver's Eye Height for SSD}

The driver eye height of $1.08 \mathrm{~m}$ that is commonly recommended is based on research that suggests average vehicle heights have decreased to $1.30 \mathrm{~m}(4.25 \mathrm{ft})$ with a comparable decrease in average eye heights to $1.08 \mathrm{~m}(3.50 \mathrm{ft})$. For large trucks, the driver eye height ranges from $1.80 \mathrm{~m}$ to $2.40 \mathrm{~m}(3.50 \mathrm{ft}$ to $7.90 \mathrm{ft})$. The recommended height for a truck driver for design is $2.33 \mathrm{~m}(7.60 \mathrm{ft})$ above the road surface.

\subsection{Object's Height for SSD}

An object height of a $0.6 \mathrm{~m}(2.0 \mathrm{ft})$ is commonly selected based on studies that have indicated that objects less than $0.60 \mathrm{~m}$ in height are less likely to cause crashes. Therefore, an object height of $0.6 \mathrm{~m}$ is considered the smallest object that could pose risk to drivers. In addition, an object height of $0.60 \mathrm{~m}$ is a good representative of the height of automobile headlights and taillights [1].

\subsection{Effect of Grades on SSD}

For roads having positive grades, braking distance can be calculated by the following equation [1] [2]:

$$
d_{b}=\frac{V^{2}}{254\left[\left(\frac{a}{9.81}\right) \pm G\right]}
$$

where,

$d_{b}$ : Braking distance on grade, $\mathrm{m}$;

$V$ : Design Speed, $\mathrm{km} / \mathrm{h}$;

a: Deceleration rate, $\mathrm{m} / \mathrm{s}^{2}$;

$G$ : Grade, rise/run, $\mathrm{m} / \mathrm{m}$.

The stopping distances needed on upgrades are shorter than on level roadways; those on downgrades are longer. The AASHTO stopping sight distances for various downgrades and upgrades are shown in Table 2. Passenger cars can use grades as steep as 4.0 to 5.0 percent without significant loss in speed below that normally maintained on level roadways. Operation of passenger cars on a 3.0 percent upgrade has only a slight effect on their speeds compared to operations on level terrain. On steeper upgrades, speeds decrease gradually with increases in the grade. On downgrades, passenger car speeds generally are slightly higher than on level terrains. Trucks generally increase speed by up to 5.0 percent on downgrades and decrease speed by 7.0 percent or more on upgrades as compared to their operation on level terrains [1] [2] [3].

\subsection{SSD for Trucks}

Trucks are heavier than passenger cars; therefore, they need a longer distance to 
Table 2. AASHTO Stopping Sight Distance on grades.

\begin{tabular}{|c|c|c|c|c|c|c|}
\hline \multirow{3}{*}{$\begin{array}{l}\text { Design Speed } \\
(\mathrm{km} / \mathrm{h})\end{array}$} & \multicolumn{6}{|c|}{ Stopping Sight Distance (m) } \\
\hline & \multicolumn{3}{|c|}{ Downgrades } & \multicolumn{3}{|c|}{ Upgrades } \\
\hline & $3 \%$ & $6 \%$ & $9 \%$ & $3 \%$ & $6 \%$ & $9 \%$ \\
\hline 20 & 20 & 20 & 20 & 19 & 18 & 18 \\
\hline 30 & 32 & 35 & 35 & 31 & 30 & 29 \\
\hline 40 & 50 & 50 & 53 & 45 & 44 & 43 \\
\hline 50 & 66 & 70 & 74 & 61 & 59 & 58 \\
\hline 60 & 87 & 92 & 97 & 80 & 77 & 75 \\
\hline 70 & 110 & 116 & 124 & 100 & 97 & 93 \\
\hline 80 & 136 & 144 & 154 & 123 & 118 & 114 \\
\hline 90 & 164 & 174 & 187 & 148 & 141 & 136 \\
\hline 100 & 194 & 207 & 223 & 174 & 167 & 160 \\
\hline 110 & 227 & 243 & 262 & 203 & 194 & 186 \\
\hline 120 & 263 & 281 & 304 & 234 & 223 & 214 \\
\hline 130 & 302 & 323 & 350 & 267 & 254 & 243 \\
\hline
\end{tabular}

stop. However, it is believed that adjustment factors for trucks are not necessary since visibility from a truck is typically better given that the driver is seated at a higher elevation above the roadway surface. Thus, this increase in the height of the driver substitutes the need for additional stopping sight distance for trucks [1] [2] [3] [4].

\subsection{Measuring and Recording Sight Distance}

In the field, stopping sight distance is measured along the travel path of vehicles and several methods are typically utilized. The first conventional procedure is called the walking method [5] [6] that involves at least two individuals, sighting and a target rods, a measuring wheel, and a chain. The target rod is usually $1.3 \mathrm{~m}$ tall representing the vehicle's height and is usually painted orange on both the top portion and bottom $0.6 \mathrm{~m}$ of the rod. The bottom $0.6 \mathrm{~m}$ portion of the target rod is the height of object for measuring stopping sight distance. The sighting rod is $1.08 \mathrm{~m}$ tall representing the driver's eye height recommended by AASHTO and is usually painted black. From any point location along the road, the observer should sight from the top of the sighting rod while the assistant moves away in the direction of travel. The assistant stops when the bottom $0.6 \mathrm{~m}$ portion of the target rod is no longer visible. The distance from the disappearing point to the observer presents the available stopping sight distance. The analysis procedure consists of comparing the recommended sight distance from AASHTO tables to the measured sight distance in the field. Given that this measurement method requires the observer to be in the travel lane with their back to traffic, measurements along the shoulder are often substituted since they are safer for 
the personnel conducting the measurement. Similar in scope to the conventional approach, modern technologies have also been utilized to measure sight distance in the field. For instance, the two-vehicle method employs two vehicles equipped with sensors that measure their spacing, two-way communication device, and a paint sprayer [4]. The vehicles calibrate their spacing to a desired sight distance. As the vehicles traverse a roadway, observers in the trailing vehicle note whether or not portions of the road meet the specified sight distance. Another similar method is the one-vehicle method that also has been used by some transportation agencies [5] [6]. This method requires one employee in a vehicle equipped with a measuring device, and a paint sprayer. The driver moves slowly through the road and watches the points at which the view opens up and marks these points by paint. Another technique that has widely been used is the computer based method, using the global positioning systems (GPS) data [7]. This method requires two vehicles, the lead vehicle equipped with modern telemetry, and the trailing vehicle equipped with logging laptop computer. The visibility of a target on the lead vehicle, monitored from the trailing vehicle, is recorded to determine if the available sight distance is sufficient. The field-based measurement approaches discussed are advantageous in that a diverse range of roadway conditions can be incorporated. That is, since there are observers on the ground, obstructions to visibility can be accounted for in a more precise manner. However, field measurement techniques are extremely time consuming and may require many years to conduct at a broad regional level. Field measurements can also lack consistency based on the measurement technique and the characteristics of the crew conducting the task. Moreover, field measurements require that individuals work in traffic which presents a significant threat to their safety. As such, a measurement approach that entails a more remote analysis of sight distance and permits a broader, regional perspective would certainly be a valuable tool for providing an initial estimate of sight distance. To address this need, a variety of approaches have been developed to use other data sources to estimate sight distance without using equipped vehicles or deploying individuals to the field. In this sense, Tsai et al. (2010) propose an algorithm to compute roadway geometric data, including roadway length, sight distance, and lane width from images, using emerging vision technology based on $2 \mathrm{D}$, and $3 \mathrm{D}$ image reconstruction [8]. Also, Shaker et al. (2011) use stereo high resolution satellite imagery for extracting the highway profiles and constructing 3D highway visualization model using a polynomial-based generic push broom model and rational function model to perform the sensor orientation [9]. Methods that use Global Positioning Systems (GPS) data to estimate sight distance have also been developed. For instance, Ben-Arieh et al. (2004) used a GPS data and B-Spline method to model highway geometric characteristics that utilized B-spline curves and a piecewise polynomial function [10]. Nehate and Rys (2006) used the geometric model developed by Ben-Arieh et al. (2004) to calculate the available sight distance on 3D combined horizontal and vertical alignment [11]. They utilized a piecewise pa- 
rametric equation in the form of cubic B-splines to represent the highway surface and sight obstructions, and the available sight distance was found analytically by examining the intersection between the sight line and the elements representing the highway surface and sight obstructions. Azimi and Hawkins (2013) proposed a method that uses vector product to derive the visibility of the centerline of the roadway from the spatial coordinates of a set of GPS data of the centerline and defined the clear zone boundaries on both sides of the roadway to determine the available sight distance at each point of the roadway [12] [13].

\subsection{Sight Distance Obstructions}

On a crest vertical curve, the road surface at some point could limit the driver's stopping sight distance. On horizontal curves, the obstruction that limits the driver's sight distance may be some physical feature outside of the traveled way, such as a longitudinal barrier, a bridge-approach fill slope, a tree, foliage, or the back slope of a cut section. Thus, it is recommended to check all road construction plans for other obstructions to sight distance [1] [2] [3] [4].

\subsection{SSD on Horizontal Alignments}

When a vehicle travels in a circular path, it undergoes a centripetal acceleration that acts toward the center of curvature. This acceleration is sustained by a component of the vehicle's weight related to the roadway super elevation, by the side friction developed between the vehicle's tires and the pavement surface, or by a combination of the two, which is occasionally equals to the centrifugal force [1] [2] [3] [4]. The design of roadway curves should be based on an appropriate relationship between design speed and radius of curvature and on their joint relationships with super elevation (roadway banking) and side friction. When a vehicle travels at constant speed on a curve super elevated so that the friction is zero, the centripetal acceleration is sustained by a component of the vehicle's weight, and no steering force is needed. A vehicle traveling faster or slower than the balance speed develops tire friction as steering effort is applied to prevent movement to the outside or to the inside of the curve. From the basic laws of mechanics, the fundamental equation that governs vehicle operation on a horizontal curve is as follows [1] [2]:

$$
\frac{0.01 e+f}{1-0.01 e f}=\frac{v^{2}}{g R}=\frac{0.0079 V^{2}}{R}=\frac{V^{2}}{127 R}
$$

where,

$$
\begin{aligned}
& \text { e: rate of roadway super elevation, percent; } \\
& \text { f. coefficient of side friction, unitless; } \\
& \text { v. vehicle speed, } \mathrm{m} / \mathrm{s} ; \\
& V \text { : vehicle speed, } \mathrm{km} / \mathrm{h} ; \\
& \text { g. gravitational constant, } 9.81 \mathrm{~m} / \mathrm{s}^{2} ;
\end{aligned}
$$

$R$ : radius of the curve measured to the vehicle's center of gravity, $\mathrm{m}$.

Values for maximum super elevation rate $(e)$ and maximum side friction coef- 
ficient $(f)$ can be determined from the AASHTO Green Book for curve design. Using these values in the curve formula results in determining a minimum curve radius for various design speeds [1]. The coefficient of friction $f$ is the friction force divided by the component of the weight perpendicular to the pavement surface. The value of the product (ef) is always small. As a result, the $(1-0.01 e f)$ term is nearly equal to 1.0 and is normally omitted in highway design. Omission of this term yields the following basic side friction equation, which is widely used in curve design [1] [2]:

$$
f=\frac{V^{2}}{127 R}-0.01 e
$$

The minimum radius is a limiting value of curvature for a given design speed and is determined from the maximum rate of super elevation and the maximum side friction coefficient. Use of sharper curvature for that design speed would call for super elevation beyond the limit considered practical or for operation with tire friction beyond what is considered comfortable by many drivers, or both. The minimum radius of curvature is based on a threshold of driver comfort that is suitable to provide a margin of safety against skidding and vehicle rollover. The minimum radius of curvature, $R_{\min }$ can be determined directly from the following equation [1] [2]:

$$
R_{\min }=\frac{V^{2}}{127\left(0.01 e_{\max }+f_{\max }\right)}
$$

If there are sight obstructions (such as walls, cut slopes, buildings, and barriers) on the inside of horizontal curves and their removal to increase sight distance is impractical, a design may need adjustment in the highway alignment. For general use in design of a horizontal curve, the horizontal sight line is a chord of the curve, and the stopping sight distance is measured along the centerline of the inside lane around the curve, as shown in Figure 2. The horizontal sight line offset (HSO) can be determined from Equation (6). The equation applies only to circular curves longer than the sight distance for the specified design speed [1] [2]:

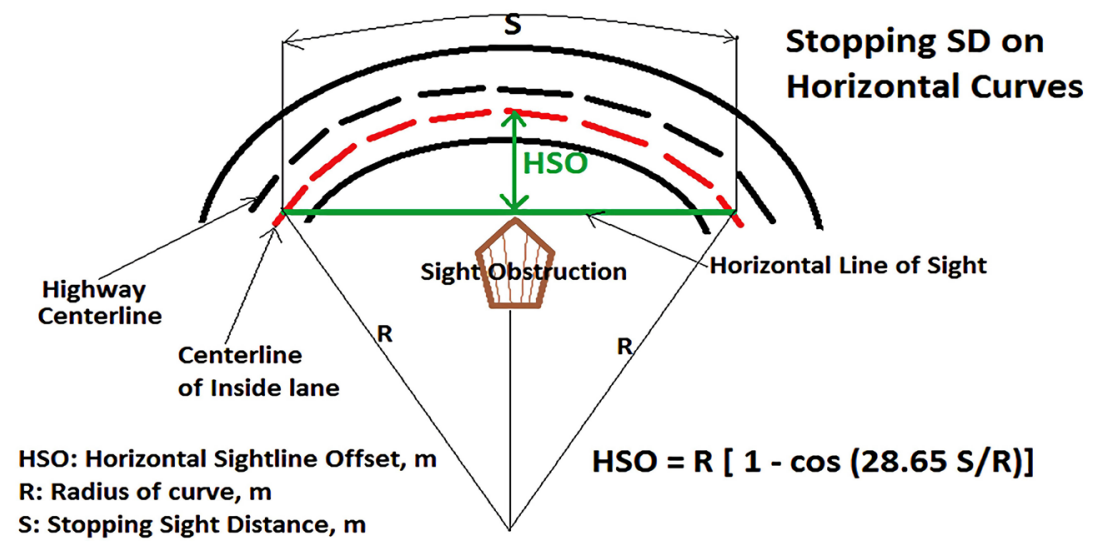

Figure 2. AASHTO SSD criteria on Horizontal alignments. 


$$
H S O=R\left[1-\cos \left(\frac{28.65 S}{R}\right)\right]
$$

where,

HSO: Horizontal Sightline Offset, m;

$S$ : Stopping Sight Distance, m;

$R$ : Radius of curve, $\mathrm{m}$.

Where adequate stopping sight distance is not available because of a sight obstruction, alternative designs must be used, such as increasing the offset to the obstruction, increasing the radius, or reducing the design speed [1] [2] [3].

\subsection{SSD on Crest Vertical Curves}

Crest vertical curves should be designed to provide at least the stopping sight distance that is a major design control. Minimum lengths of crest vertical curves based on sight distance criteria generally are satisfactory from the standpoint of safety, comfort, and appearance [1] [2] [3] [4]. The basic equations for length of a crest vertical curve in terms of algebraic difference in grade and sight distance criteria are as follows [1] [2]:

when $S$ is less than $L$ :

$$
L=\frac{A S^{2}}{100\left(\sqrt{2 h_{1}}+\sqrt{2 h_{2}}\right)^{2}}
$$

when $S$ is greater than $L$ :

$$
L=2 S-\frac{200\left(\sqrt{h_{1}}+\sqrt{h_{2}}\right)^{2}}{A}
$$

where,

$L$ : Length of vertical curve, m;

A: Algebraic difference in grade, percent;

$S$ : Sight distance, m;

$h_{1}$ : Driver's Eye Height above roadway surface, m;

$h_{2}$ : Object's Height above roadway surface, $\mathrm{m}$.

When the height of the eye and the height of object are 1.08 and $0.60 \mathrm{~m}(3.50$ $\mathrm{ft}$ and $2.0 \mathrm{ft}$ ), respectively, as used for stopping sight distance, the equations become:

when $S$ is less than $L$ :

$$
L=\frac{A S^{2}}{658}
$$

when $S$ is greater than $L$ :

$$
L=2 S-\frac{658}{A}
$$

Rate of vertical curvature, $K$, is usually used in the design calculation, which is the length of curve per percent algebraic difference in intersecting grades, (i.e. $K$ $=L / A$ ). Figure 3 shows the AASHTO parameters used in determining the length 


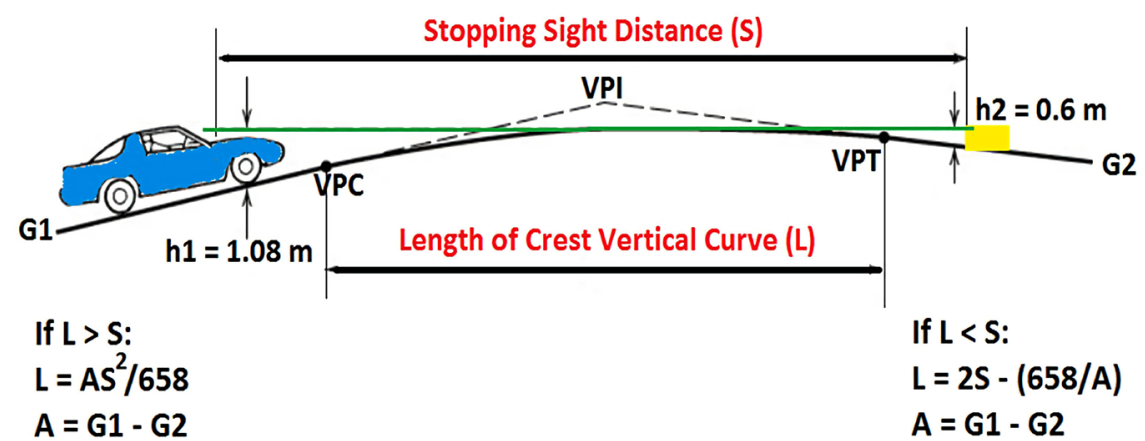

Figure 3. SSD parameters used in design of crest vertical curves.

of a crest vertical curve to provide stopping sight distance. For night driving on highways without lighting, the headlights of the vehicle directly illuminate the length of visible roadway. Thus, stopping sight distance values exceed road-surface visibility distances afforded by the low-beam headlights regardless of whether the roadway profile is level or curving vertically. Since the headlight, mounting height (typically about $0.60 \mathrm{~m}$ ) is lower than the driver eye height used for design $(1.08 \mathrm{~m})$, the sight distance to an illuminated object is controlled by the height of the vehicle headlights rather than by the direct line of sight. In addition, drivers are aware that visibility at night is less than during the day, regardless of road features, and they may therefore be more attentive and alert [1] [2] [3].

\subsection{SSD on Sag Vertical Curves}

Design controls for sag vertical curves differ from those for crests, and separate design values are needed. The headlight sight distance is used to determine the length of a sag vertical curve, and the values determined for stopping sight distances are within these limits. As in the case of crest vertical curves, it is convenient to express the design control in terms of the $K$ rate for all values of $A$. When a vehicle traverses a sag vertical curve at night, the portion of highway lighted ahead is dependent on the position of the headlights and the direction of the light beam. A headlight height of $0.60 \mathrm{~m}(2.0 \mathrm{ft})$ and a 1-degree upward divergence of the light beam from the longitudinal axis of the vehicle are assumed in the design. The following equations are used to determine the length of sag vertical curves based on sight distance criteria [1] [2]:

when $S$ is less than $L$ :

$$
L=\frac{A S^{2}}{200[0.6+S(\tan 1)]}=\frac{A S^{2}}{120+3.5 S}
$$

when $S$ is greater than $L$ :

$$
L=2 S-\frac{200[0.6+S(\tan 1)]}{A}=2 S-\frac{120+3.5 S}{A}
$$

where,

$L$ : Length of sag vertical curve, m; 
A: Algebraic difference in grades, percent;

$S$ : Stopping sight distance (Light beam distance), $\mathrm{m}$.

The light beam distance is approximately the same as the stopping sight distance, and it is appropriate to use stopping sight distances for different design speeds as the value of $S$ in the above equations [1] [2]. Figure 4 shows the parameters used in the design of a sag vertical curve.

\subsection{SSD at Under Crossings}

Sag vertical curves under passing a structure should be designed to provide the minimum recommended stopping sight distance for sag curves [1] [2] [3] [4]. The general equations for sag vertical curve length at under crossings are [1] [2]:

when $S$ is less than $L$ :

$$
L=\frac{A S^{2}}{800\left[C-\frac{h_{1}-h_{2}}{2}\right]}
$$

when $S$ is greater than $L$ :

$$
L=2 S-\frac{800\left[C-\frac{h_{1}-h_{2}}{2}\right]}{A}
$$

where,

$L$ : Length of Sag Vertical Curve, m;

$S$ : Stopping Sight Distance, $\mathrm{m}$;

$C$ : Vertical Clearance, m;

$h_{1}$ : height of eye, m;

$h_{2}$ : height of object, $\mathrm{m}$;

$A$ : Algebraic difference in grades, percent.

AASHTO uses an eye height of $2.4 \mathrm{~m}(8.0 \mathrm{ft})$ for a truck driver and an object height of $0.6 \mathrm{~m}(2.0 \mathrm{ft})$ for the taillights of a vehicle. Substituting these values, the above equations become [1] [2]:

when $S$ is less than $L$ :

$$
L=\frac{A S^{2}}{800(C-1.5)}
$$

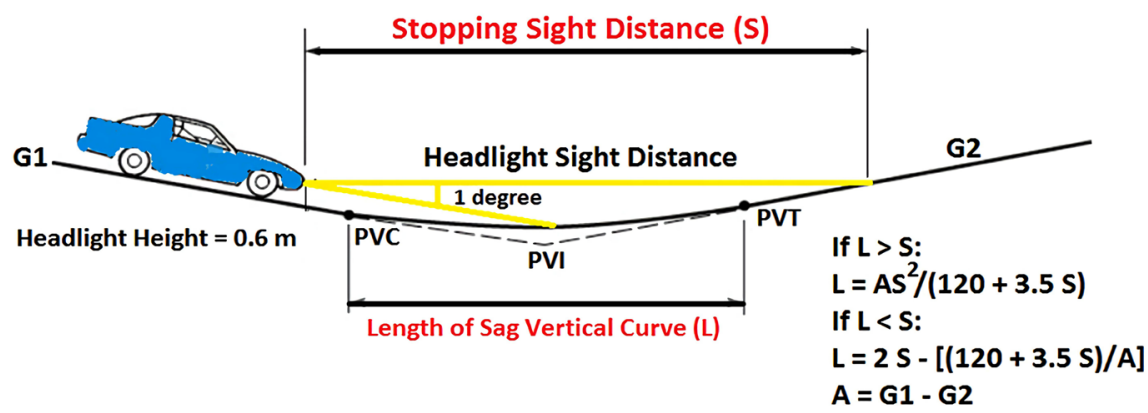

Figure 4. SSD parameters used in design of sag vertical curves. 
when $S$ is greater than $L$ :

$$
L=2 S-\frac{800(C-1.5)}{A}
$$

Figure 5 shows the AAHSTO parameters used in the design of sag vertical curves under passing a structure.

\section{Decision Sight Distance (DSD)}

While stopping sight distances are usually sufficient to allow average drivers to come to a complete stop under ordinary circumstances, however, greater distances are preferred where drivers must make instantaneous decisions, where information is difficult to perceive, or when unexpected or unusual maneuvers are needed. In these circumstances, decision sight distance provides the greater visibility distance that drivers need. Decision sight distance is defined as the distance required for a driver to detect an unexpected source or hazard in a roadway, recognize the threat potential, select an appropriate speed and path, and complete the required maneuver safely and efficiently [1] [2] [3] [4]. Most traffic situations presented on highways require stopping sight distance at a minimum; however, decision sight distance is also recommended for safer and smoother operations. For example, long traffic queues, problems of driver expectancy, and high traffic volumes require more time and distances to accommodate normal vehicle maneuvers of lane changing, speed changes and path changes.

\subsection{Comparison between SSD and DSD}

The distinction between stopping sight distance and decision sight distance must be well understood. Stopping sight distance is applied where only one obstacle must be seen in the roadway and dealt with. Decision sight distance applies when traffic conditions are complex, and driver expectancies are different from normal traffic situation. The difference between stopping in the context of decision sight distance and stopping sight distance is that the vehicle should stop for some complex traffic condition, such as a queue of vehicles or hazardous conditions, rather than an object in the roadway. The values of decision sight distance are greater than the values of stopping sight distance because they provide the driver an additional margin for error and afford sufficient length to maneuver at

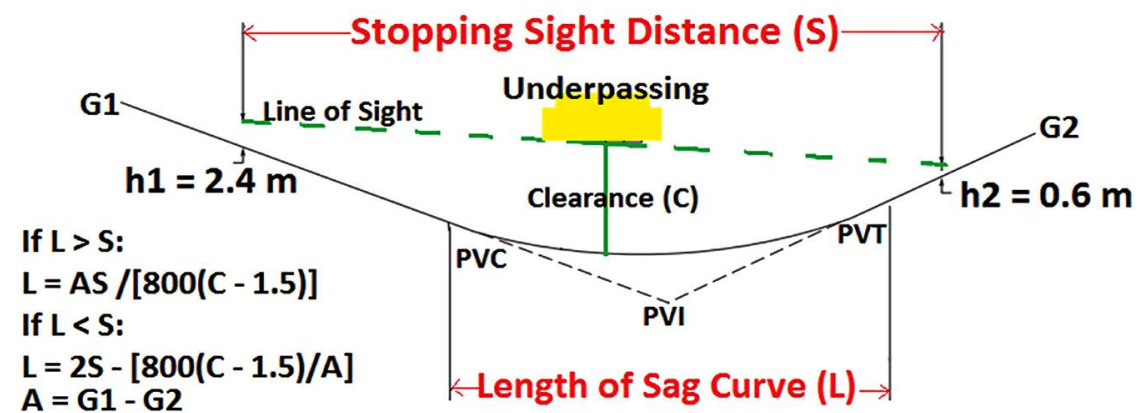

Figure 5. SSD parameters used in design of under passing sag curves. 
the same or reduced speed rather than to stop. The added complexity in DSD requires additional perception-reaction time prior to applying the brakes to begin to slow the vehicle to a stop or change the speed or travel path. This allows the driver additional time to detect and recognize the roadway or traffic situation, identify alternative maneuvers, and initiate a response on the highway. AASHTO Greenbook (2018 and 2011) suggest that about 3.0 to 9.0 seconds are required for detecting and understanding the unexpected traffic situation with an additional 5.0 to 5.5 seconds required to perform the appropriate maneuver compared to only 2.5 seconds as perception reaction time in stopping sight distance calculations. Similar to the stopping sight distance, AASHTO Greenbook

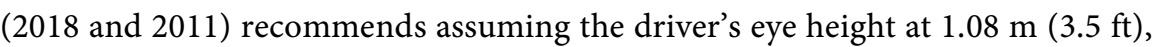
and the object height as $0.60 \mathrm{~m}(2.0 \mathrm{ft})$ for decision sight distance calculations.

\subsection{Cases of DSD}

Decision sight distance is different for urban versus rural conditions and for stopping versus maneuvering within the traffic stream conditions. Consequently, there are five different cases for decision sight distance as follows [1] [2] [3]:

- Avoidance Maneuver A: Stop on Rural Road - $(t=3.0 \mathrm{sec})$,

- Avoidance Maneuver B: Stop on Urban Road - $(t=9.1 \mathrm{sec})$,

- Avoidance Maneuver C: Speed/Path/Direction Change on Rural Road - $(t$ between 10.2 and $11.2 \mathrm{sec}$ ),

- Avoidance Maneuver D: Speed/Path/Direction Change on Suburban Road ( $t$ between 12.1 and $12.9 \mathrm{sec}$ ),

- Avoidance Maneuver E: Speed/Path/Direction Change on Urban Road - $(t$ between 14.0 and $14.5 \mathrm{sec}$ ).

\subsection{DSD Calculations for Stop Maneuvers A and B}

The available decision sight distance for the stop avoidance maneuvers A and B are determined as the sum of two distances, namely: 1) Reaction distance (the distance a vehicle travels from the moment a driver detects a condition or hazard in the roadway until the driver applies the brakes) and;2) Braking distance (the distance a vehicle travels from the moment the brakes are applied until the vehicle comes to a complete stop). DSD can be computed as a function of these two distances [1] [2] [3]:

$$
D S D=0.278 V T+0.039 V^{2} / a
$$

where:

$$
\begin{aligned}
& D S D=\text { decision sight distance, } \mathrm{m} ; \\
& V=\text { design speed, } \mathrm{km} / \mathrm{h} ; \\
& T=\text { Maneuver time, seconds; } \\
& a=\text { deceleration rate, } \mathrm{m} / \mathrm{s}^{2} .
\end{aligned}
$$

AASHTO Greenbook (2018 and 2011) recommends a (3.0 seconds) as a driver's reaction time for rural highways, (6.0 seconds) for sub urban highways, and a (9.1 seconds) for urban highways. AASHTO uses $\left(3.4 \mathrm{~m} / \mathrm{s}^{2}\right)$ as the deceleration 
rate for decision sight distance calculations.

\subsection{DSD Calculations for Maneuvers C D and E}

The available decision sight distances for avoidance maneuvers $\mathrm{C}, \mathrm{D}$, and $\mathrm{E}$ are determined as follows [1] [2] [3]:

$$
D S D=0.278 V T
$$

where:

$D S D=$ decision sight distance, $\mathrm{m}$;

$V=$ design speed, $\mathrm{km} / \mathrm{h}$;

$T=$ Maneuver time, seconds.

AASHTO Greenbook (2018 and 2011) recommends a (10.2 to 11.2 seconds for maneuver $\mathrm{C}$ on rural roads, a 2.1 to 12.9 seconds for maneuver $\mathrm{D}$ on suburban roads, and a 14.0 to 14.5 seconds for maneuver $\mathrm{E}$ on urban roads) as the driver's reaction time. Figure 6 provides an illustration of the recommended AASHTO criteria on DSD. The recommended height of the driver's eye above the road surface is $(1.08 \mathrm{~m})$ and the height of an object above the roadway is (0.6 $\mathrm{m})$. Table 3 shows the AASHTO recommended decision sight distances for various maneuvers. As can be seen in the table, shorter distances are generally needed for rural roads and for locations where a stop is the appropriate maneuver. If it is not practical to provide decision sight distance on some highways,

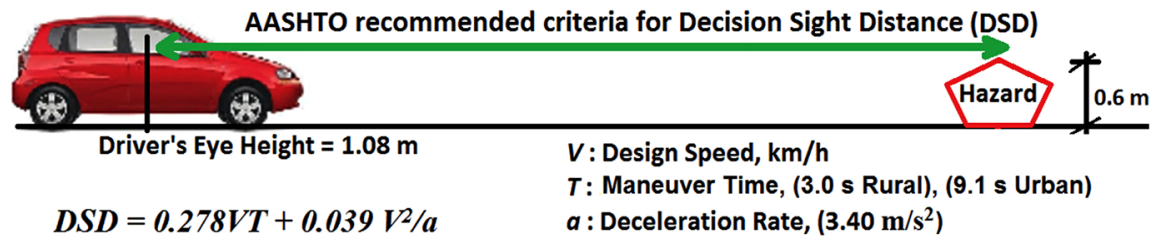

Figure 6. Recommended AASHTO criteria on DSD.

Table 3. AASHTO recommended decision sight distance.

\begin{tabular}{cccccc}
\hline & \multicolumn{5}{c}{ Decision Sight Distance, meters } \\
\cline { 2 - 6 } $\begin{array}{c}\text { Design Speed } \\
(\mathrm{km} / \mathrm{h})\end{array}$ & A & B & C & D & E \\
\cline { 2 - 6 } & 70 & 155 & 145 & 170 & 195 \\
\hline 50 & 195 & 170 & 205 & 235 \\
60 & 95 & 235 & 200 & 235 & 275 \\
70 & 115 & 280 & 230 & 270 & 315 \\
80 & 140 & 325 & 270 & 315 & 360 \\
90 & 170 & 370 & 315 & 355 & 400 \\
100 & 200 & 420 & 330 & 380 & 430 \\
110 & 235 & 470 & 360 & 415 & 470 \\
120 & 265 & 525 & 390 & 450 & 510 \\
130 & 305 & & & & \\
\hline
\end{tabular}


attention should be given to the use of suitable traffic control devices for providing advance warning of the conditions that are likely to be encountered [1] [2] [3].

\section{Passing Sight Distance (PSD)}

Passing sight distance (PSD) is the distance that drivers must be able to see along the road ahead to safely and efficiently initiate and complete passing maneuvers of slower vehicles on two-lane, two-way highways using the lane normally reserved for opposing traffic [1] [2] [3]. PSD is a consideration along two-lane roads on which drivers may need to assess whether to initiate, continue, and complete or abort passing maneuvers. In the US, many roads are two-lane, two-way highways on which faster vehicles frequently overtake slower moving vehicles. In order to secure a safe passing maneuver, the passing driver should be able to see a sufficient distance ahead, clear of traffic, to complete the passing maneuver without cutting off the passed vehicle before meeting an opposing vehicle [1] [2] [3]. Therefore, passing sight distance (PSD) is considered an important factor in both the design of two-lane, two-way (TLTW) highways and the marking of passing zones (PZ) and no-passing zones (NPZ) on two-lane, two-way highways. The efficiency of traffic operation of many TLTW highways depends on how often faster drivers are able to pass slower drivers. For example, where faster drivers encounter a slower driver but are unable to pass, vehicle platoons are built up, and cause a decrease in the level of service and inversely affect safety, fuel consumption and emissions. The capacity of a two-lane, two-way road is increased if a large percentage of the roadway's length can be used for passing maneuvers [14] [15] [16].

\subsection{PSD on Multilane Highways}

There is no need to consider passing sight distance on multilane highways that have two or more traffic lanes in each direction of travel, because passing maneuvers are expected to occur within the limits of the traveled way for each direction of travel. However, multilane roadways should have continuously adequate stopping sight distance, with greater-than-design sight distances preferred [1] [2] [3].

\subsection{Marking of Passing Zones on Two-Lane Highways}

The design of two-lane highway is based on the AASHTO Green book criteria, however, the marking of passing zones (PZs) and No-passing zones (NPZs) is based on the Manual on Uniform Traffic Control Devices for Streets and Highways (MUTCD) criteria. The use of separate PSD criteria for design and marking is justified based on different needs in design and traffic operation. Since the current US highway system operates with relatively low level of crashes related to passing maneuvers and PSD, which indicates that the highway system can be operated safely with passing and no-passing zones marked with the current 
MUTCD criteria, therefore changing the current MUTCD PSD criteria to equal the AASHTO criteria, or some intermediate value, is not recommended because it would decrease the frequency and length of passing zones on two-lane, two-way highways. This would decrease the traffic level of service and might encourage illegal passes at locations where passing maneuvers are currently legal [14] [15] [16]. As such, the AASHTO Green Book (2018 and 2011) has adapted the MUTCD PSD values for the design of TLTW highways.

\subsection{Driver's Eye Height and Object's Height for PSD}

AASHTO Green book (2018 and 2011) uses both the height of the driver's eye and the object height as $1.08 \mathrm{~m}(3.5 \mathrm{ft})$ above the road surface [1] [2]. This object height is based on a vehicle height of $1.33 \mathrm{~m}(4.35 \mathrm{ft})$, which $\mathrm{h}$ represents the 15th percentile of vehicle heights in the current passenger car population, less an allowance of $0.25 \mathrm{~m}(0.85 \mathrm{ft})$, which is a near-maximum value for the portion of the vehicle height that needs to be seen for another driver to recognize a vehicle. The choice of an object height equal to the driver eye height makes design of passing sight distance reciprocal (i.e. when the driver of the passing vehicle can see the opposing vehicle, the driver of the opposing vehicle can also see the passing vehicle). Passing sight distances calculated on this basis are also considered adequate for night conditions because headlight beams of an opposing vehicle generally can be seen from a greater distance than a vehicle can be recognized in the daytime [1] [2] [3].

\subsection{PSD Model Assumptions}

While there may be occasions, where multiple passing occurs when two or more vehicles pass a single vehicle, or a single vehicle passes two or more vehicles. However, it is not practical to assume such conditions in developing minimum passing sight distance criteria. Instead, PSD is determined for a single vehicle passing a single vehicle [1] [2] [3]. Longer passing sight distances are recommended in the design and these locations can accommodate for an occasional multiple passing. AASHTO Greenbook (2018 and 2011) uses two theoretical models for the sight distance needs of passing drivers based on the assumption that a passing driver will abort the passing maneuver and return to his or her normal lane behind the overtaken vehicle if a potentially conflicting vehicle comes into view before reaching a critical position in the passing maneuver beyond which the passing driver is committed to complete the maneuver. The Glennon (1998) model assumes that the critical position occurs where the passing sight distance to complete the maneuver is equal to the sight distance needed to abort the maneuver [14]. The Hassan et al. (1996) model assumes that the critical position occurs where the passing sight distances to complete or abort the maneuver are equal or where the passing and passed vehicles are abreast, whichever occurs first [15]. The following assumptions are made regarding the driver behavior in the passing maneuvers and PSD calculations based on the 
Glennon (1998) and Hassan et al. (1996) models [1] [2] [14] [15]:

- The speeds of the passing and opposing vehicles are equal to the design speed.

- The overtaken vehicle travels at uniform speed.

- The Speed differential between the passing and overtaken vehicles is $19 \mathrm{~km} / \mathrm{h}$ (12 mph).

- The passing vehicle has sufficient acceleration capability to reach the specified speed differential relative to the overtaken vehicle by the time it reaches the critical position, which generally occurs about 40 percent of the way through the passing maneuver.

- The lengths of the passing and overtaken vehicles are $5.8 \mathrm{~m}(19.0 \mathrm{ft})$.

- The passing driver's perception-reaction time in deciding to abort passing a vehicle is $1.0 \mathrm{sec}$.

- If a passing maneuver is aborted, the passing vehicle will use a deceleration rate of $3.4 \mathrm{~m} / \mathrm{s}^{2}\left(11.2 \mathrm{ft} / \mathrm{s}^{2}\right)$, the same deceleration rate used in stopping sight distance criteria.

- For a completed or aborted pass, the space headway between the passing and overtaken vehicles is $1.0 \mathrm{sec}$.

- The minimum time clearance between the passing and opposed vehicles at the point at which the passing vehicle returns to its normal lane is $1.0 \mathrm{sec}$.

\subsection{PSD Calculations on Two-Lane Highways}

AASHTO Green Book of (2018 and 2011) does not provide specific formulae for calculating the required PSD, however, previous versions of AASHTO Green Book (2001 and 2004) use the minimum passing sight distance for TLTW highways as the sum of the following four distances:

1) $d_{1}=$ Distance traversed during perception and reaction time and during the initial acceleration to the point of encroachment on the opposing lane, and is calculated as follows:

$$
d_{1}=0.278 t_{i}\left[v-m+\left(a t_{i} / 2\right)\right]
$$

where;

$t_{i}=$ time of initial maneuver, ranges from (3.6 to 4.5$) \mathrm{sec}$,

$a=$ average acceleration, ranges from $(2.25$ to 2.41$) \mathrm{km} / \mathrm{h} / \mathrm{s}$,

$V=$ average speed of passing vehicle $(\mathrm{km} / \mathrm{h})$,

$m=$ difference in speed of overtaken vehicle and passing vehicle $(\mathrm{km} / \mathrm{h})$.

2) $d_{2}=$ Distance traveled while the passing vehicle occupies the left lane, and is determined as follows:

$$
d_{2}=0.278 v t_{2}
$$

where;

$t_{2}=$ time passing vehicle occupies the left lane, ranges from (9.3 to 11.3) sec,

$v=$ average speed of passing vehicle $(\mathrm{km} / \mathrm{h})$.

3) $d_{3}=$ Distance between the passing vehicle at the end of its maneuver and the opposing vehicle (the clearance length), ranges from (30.0 to 90.0) $\mathrm{m}$. 
4) $d_{4}=$ Distance traversed by an opposing vehicle for two-thirds of the time the passing vehicle occupies the left lane, or 2/3 of $d_{2}$ above, and ranges from (97.0 to 209.0) m. Figure 7 shows the AASHTO 2004 model for calculating PSD.

Table 4 shows the minimum values of PSD required for the design of two-lane highways based on AASHTO 2018 and 2011 Green Books. These values assume that a passing driver will abort the passing maneuver and return to his or her normal lane behind the overtaken vehicle if a potentially conflicting vehicle comes into view before reaching a critical position in the passing maneuver beyond which the passing driver is committed to complete the maneuver [1] [2].

\subsection{Warrants for No-Passing Zones}

Each passing zone along a length of roadway with sight distance ahead should be

AASHTO (2004) PASSING SIGHT DISTANCE (PSD)

d1 : Initial Maneuver Distance
d2 : Left Lane Distance

PSD $=d 1+d 2+d 3+d 4$

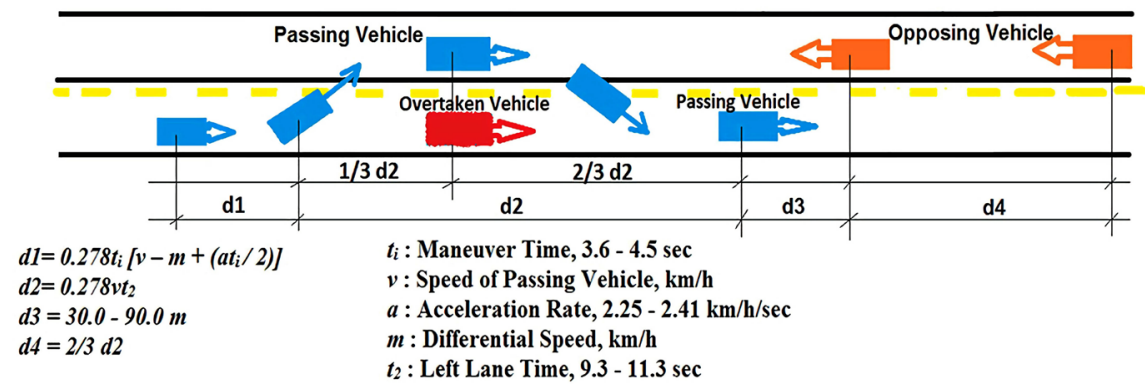

Figure 7. AASHTO (2004) model for PSD calculations.

Table 4. Minimum PSD values for design of two-lane highways.

\begin{tabular}{cccc}
\hline $\begin{array}{c}\text { Design Speed } \\
(\mathrm{km} / \mathrm{h})\end{array}$ & \multicolumn{2}{c}{ Assumed Speeds $(\mathrm{km} / \mathrm{h})$} & $\begin{array}{c}\text { Minimum Passing Sight Distance } \\
(\mathrm{m})\end{array}$ \\
\cline { 2 - 3 } 30 & 11 & 30 & 120 \\
40 & 21 & 40 & 140 \\
50 & 31 & 50 & 160 \\
60 & 41 & 60 & 180 \\
70 & 51 & 70 & 210 \\
80 & 61 & 80 & 245 \\
90 & 71 & 90 & 280 \\
100 & 81 & 100 & 320 \\
110 & 91 & 110 & 355 \\
120 & 101 & 120 & 395 \\
130 & 111 & 130 & 440 \\
\hline
\end{tabular}

Source: AASHTO Green Book, 2011, Table 3 \& Table 4. 
equal to or greater than the minimum passing sight distance should be as long as practical [1] [2] [3]. The criteria for marking passing and no-passing zones on two-lane highways are established by the MUTCD. Passing zones are not marked directly. Rather, the warrants for no-passing zones are set by the MUTCD, and passing zones merely happen where no-passing zones are not warranted [17]. Table 5 shows the MUTCD PSD warrants for no-passing zones. These criteria are based on prevailing off-peak 85th-percentile speeds rather than the design speeds.

\subsection{Minimum Lengths of PZs}

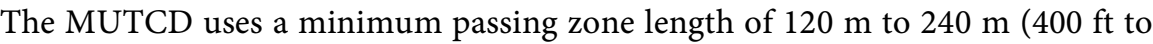
$800 \mathrm{ft}$ ) depending on the $85^{\text {th }}$ percentile speed limit, (i.e. where two no-passing zones come within $120 \mathrm{~m}$ to $240 \mathrm{~m}$ of one another, the no-passing barrier stripe should be continued between them). Table 6 shows the minimum passing zone Lengths to be Included in marking of PZs and NPZs [1] [2] [17]. Figure 8 shows the AASHTO and MUTCD criteria for PSD and marking of NPZs.

Table 5. MUTCD warrants for NPZs.

\begin{tabular}{cc}
\hline 85th percentile speed Limit $(\mathrm{km} / \mathrm{h})$ & Minimum Passing Sight Distance $(\mathrm{m})$ \\
\hline 40 & 140 \\
50 & 160 \\
60 & 180 \\
70 & 210 \\
80 & 245 \\
90 & 280 \\
100 & 320 \\
110 & 355 \\
120 & 395 \\
130 & 440 \\
\hline
\end{tabular}

Table 6. Minimum lengths of PZs.

\begin{tabular}{cc}
\hline 85th Percentile Speed Limit $(\mathrm{km} / \mathrm{h})$ & Minimum Passing Zone Length $(\mathrm{m})$ \\
\hline 40 & 140 \\
50 & 180 \\
60 & 210 \\
70 & 240 \\
80 & 240 \\
90 & 240 \\
100 & 240 \\
110 & 240 \\
120 & 240 \\
\hline
\end{tabular}


AASHTO 2011 and MUTCD 2012 criteria for Passing Sight Distance (PSD) and NPZ

Min. Passing Zone Length $=120 \mathrm{~m}-240 \mathrm{~m}$ (depending on Highway Speed)

Min. PSD $=210 \mathrm{~m}$ for Highway Speed of $70 \mathrm{~km} / \mathrm{h}$

Min. PSD $=320 \mathrm{~m}$ for Highway Speed of $100 \mathrm{~km} / \mathrm{h}$

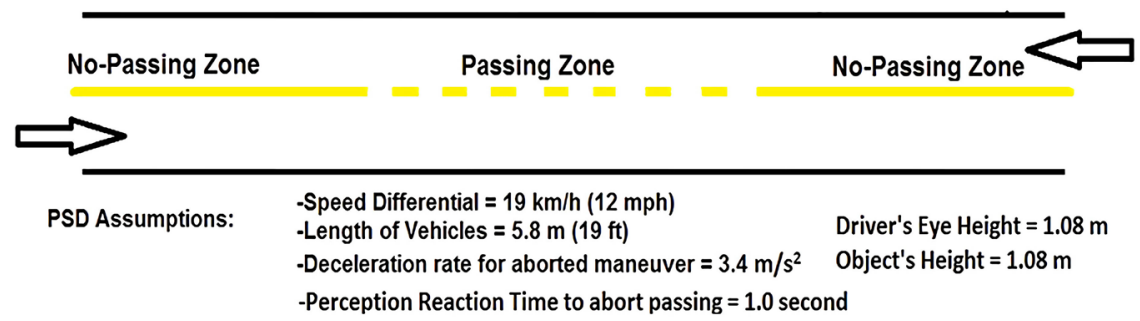

Figure 8. AASHTO and MUTCD criteria for PSD and marking of NPZs.

\subsection{PSD on Horizontal Curves}

The minimum passing sight distance for a two-lane road is greater than the minimum stopping sight distance at the same design speed [1] [2] [3] [4]. To stick with those greater sight distances, Equation (6) for SSD on curves is directly applicable to passing sight distance but is of limited practical value except on long curves, because it would be difficult to maintain passing sight distance on other than very flat curves. Therefore, design for passing sight distance should be only limited to tangents and very flat curves. Even in level terrain, provision of passing sight distance would need a clear area inside each curve that would extend beyond the normal right-of-way line [1] [2] [3] [18]-[25].

\subsection{PSD on Crest Vertical Curves}

Length values of crest vertical curves for passing sight distance differ from those for stopping sight distance because of the different sight distance and object height criteria. Using the $1.08 \mathrm{~m}(3.50 \mathrm{ft})$ height of object results in the following formulas [1] [2]:

when $S$ is less than $L$ :

$$
L=\frac{A S^{2}}{864}
$$

when $S$ is greater than $L$ :

$$
L=2 S-\frac{864}{A}
$$

where,

$L$ : Length of vertical curve, m;

$A$ : Algebraic difference in grade, percent;

$S$ : Passing sight distance, $\mathrm{m}$.

The minimum lengths of crest vertical curves are substantially longer than those for stopping sight distances [1] [2] [3]. The extent of difference is evident by the values of $K$, or length of vertical curve per percent change in A. Figure 9 shows the parameters used in determining the length of crest vertical curve based on PSD. Table 7 shows the minimum lengths of crest vertical curve as 
Table 7. PSD design controls for crest vertical curves.

\begin{tabular}{ccc}
\hline Design Speed $(\mathrm{km} / \mathrm{h})$ & Passing Sight Distance $(\mathrm{m})$ & Rate of Vertical Curvature, $\mathrm{K}$ \\
\hline 30 & 120 & 17 \\
40 & 140 & 23 \\
50 & 160 & 30 \\
60 & 180 & 38 \\
70 & 210 & 51 \\
80 & 245 & 69 \\
90 & 280 & 91 \\
100 & 320 & 119 \\
110 & 355 & 146 \\
120 & 395 & 181 \\
130 & 440 & 224 \\
\hline
\end{tabular}

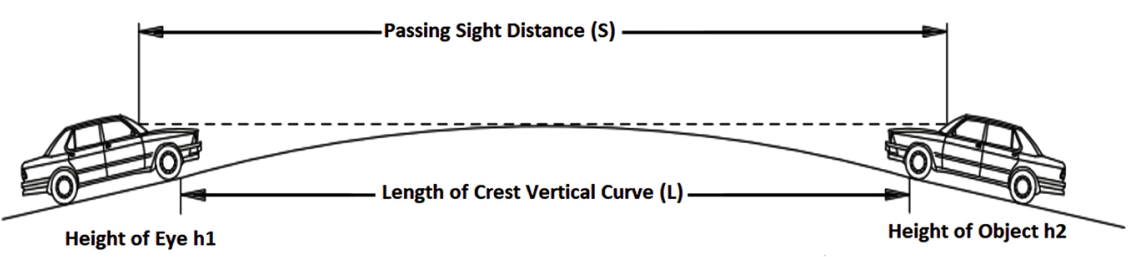

\section{$h 1=h 2=1.08 \mathrm{~m}=3.5 \mathrm{ft}$}

Figure 9. PSD parameters on crest vertical curves.

determined by PSD. Generally, it is impractical to design crest vertical curves that provide passing sight distance because of high cost and the difficulty of fitting the resulting long vertical curves to the terrain. Normally, passing sight distance is provided only at locations where combinations of alignment and profile do not need significant grading [1] [2].

\section{Conclusions}

Sight distance is the length of highway a driver needs to be able to see clearly. Sight distance is one of the important areas in highway geometric design. For safety of highway operations, the designer must provide sight distances of sufficient length along the highway that most drivers can control their vehicles to avoid collision with other vehicles and objects that conflict with their path. Three types of sight distances are to be considered in the design of highway alignments and segments: stopping, decision, and passing sight distance. The American Association of State Highway and Transportation Officials (AASHTO) has defined acceptable limits for stopping, decision, and passing sight distances based on analysis of safety requirements. Although greater length is desirable, sight distance at every point along the highway should be at least that required for a below-average driver or vehicle to stop in this distance. Stopping sight dis- 
tance is the sum of two distances: the distance traversed by the vehicle from the instant the driver sights an object necessitating a stop to the instant the brakes are applied and the distance required to stop the vehicle from the instant brake application begins. Mostly, the stopping sight distance is an adequate sight distance for roadway design. However, there are cases where it may not be appropriate. In areas where information about navigation or hazards must be observed by the driver, or where the driver's visual field is cluttered, the stopping sight distance may not be adequate. In addition, there are avoidance maneuvers that are safer than stopping, but require more reaction time by the driver. These may not be possible if the minimum stopping sight distance is used for design. In these instances, the proper sight distance to use is the decision sight distance. Various design values for the decision sight distance have been developed from research by AASHTO. The design engineer will decide when to use the decision sight distance. Providing the extra sight distance will probably increase the cost of a project, but it will also increase safety. The decision sight distance should be provided in those areas that need the extra margin of safety, but it isn't needed continuously in those areas that don't contain potential hazards. Passing sight distance is a critical component of two-lane highway design. The capacity of a two-lane roadway is greatly increased if a large percentage of the roadway's length can be used for passing. However, providing a sufficient passing sight distance over large portions of the roadway can be very expensive. Determining the passing sight distance required for a given roadway is best accomplished using a simplified AASHTO model. The passing sight distance can be divided into four distance portions:

$d_{1}$ : The distance the passing vehicle travels while contemplating the passing maneuver, and while accelerating to the point of encroachment on the left lane.

$d_{2}$ : The length of roadway that is traversed by the passing vehicle while it occupies the left lane.

$d_{3}$ : The clearance distance between the passing vehicle and the opposing vehicle when the passing vehicle returns to the right lane.

$d_{4}$ : The distance that the opposing vehicle travels during the final $2 / 3$ of the period when the passing vehicle is in the left lane.

\section{Conflicts of Interest}

The authors declare no conflicts of interest regarding the publication of this paper.

\section{References}

[1] AASHTO (2018) A Policy on Geometric Design of Highways and Streets. 7th Edition, The American Association of State Highway and Transportation Officials, Washington DC.

[2] AASHTO (2011) A Policy on Geometric Design of Highways and Streets. 6th Edition, The American Association of State Highway and Transportation Officials, Washington DC. 
[3] AASHTO (2004) A Policy on Geometric Design of Highways and Streets. 5th Edition, The American Association of State Highway and Transportation Officials, Washington DC.

[4] AASHTO (2001) A Policy on Geometric Design of Highways and Streets. 4th Edition, The American Association of State Highway and Transportation Officials, Washington DC.

[5] Brown, R.L. and Hummer, J.E. (2000) Determining the Best Method for Measuring No-Passing Zones. Transportation Research Record No. 1701, TRB. https://doi.org/10.3141/1701-08

[6] Rose, E.R., Hawkins, H.G., Holick, A.J. and Bligh, R.P. (2004) Evaluation of Traffic Control Devices: First Year Activities. Texas Transportation Institute, The Texas A\&M University System, College Station, TX.

[7] Polus, A., Livneh, M. and Frischer, B. (2000) Evaluation of the Passing Process on Two Lane Rural Highways. Transportation Research Record, No. 1701, 53-60. https://doi.org/10.3141/1701-07

[8] Tsai, Y., Hu, Z. and Wang, Z. (2010) Vision-Based Roadway Geometry Computation. Journal of Transportation Engineering, 136, 223-233. https://doi.org/10.1061/(ASCE)TE.1943-5436.0000073

[9] Shaker, A., Yan, W.Y. and Easa, S. (2011) Construction of Digital 3D Highway Model Using Stereo IKONOS Satellite Imagery. Geocartography International, 26, 49-67. https://doi.org/10.1080/10106049.2010.537785

[10] Ben-Arieh, D., Chang, S., Rys, M. and Zhang, G. (2004) Geometric Modeling of Highways Using Global Positioning System Data and B-Spline Approximation. Journal of Transportation Engineering, 130, 632-636. https://doi.org/10.1061/(ASCE)0733-947X(2004)130:5(632)

[11] Nehate, G. and Rys, M. (2006) 3D Calculation of Stopping-Sight Distance from GPS Data. Journal of Transportation Engineering, 132, 691-698. https://doi.org/10.1061/(ASCE)0733-947X(2006)132:9(691)

[12] Azimi, M. and Hawkins, H. (2013) Algorithm for Analyzing Horizontal Sight Distance from Lane Centerline Coordinates. Transportation Research Record, No. 2358, 12-19. https://doi.org/10.3141/2358-02

[13] Kim, Y., Rana, S. and Wise, S. (2004) Exploring Multiple Viewshed Analysis Using Terrain Features and Optimization Techniques. Computers and Geosciences, 30, 1019. https://doi.org/10.1016/j.cageo.2004.07.008

[14] Glennon, J.C. (1998) New and Improved Model of Passing Sight Distance on Two-Lane Highways. Transportation Research Record No. 1195. TRB, National Research Council, Washington DC.

[15] Hassan, Y., Easa, S.M. and Abd El Halim, A.O. (1996) Passing Sight Distance on Two Lane Highways: Review and Revision. Transportation Research Part A, 30, 453-467. https://doi.org/10.1016/0965-8564(95)00032-1

[16] Harwood, D.W., Gilmore D.K., Richard, K.R., Dunn, J.M. and Sun, C. (2008) Passing Sight Distance Criteria, NCHRP Report 605, Transportation Research Board.

[17] FHWA (2012) Manual on Uniform Traffic Control Devices.

[18] Abdulhafedh, A. (2019) An Innovative GIS Method for Evaluating the Visibility of the Road Using the ArcMap-Tools. Open Access Library Journal, 6, e5586. https://doi.org/10.4236/oalib.1105586

[19] Berbel, D.C., Castro, M., Medina, L.C. and Maria, S.P.G. (2014) Sight Distance Studies on Roads: Influence of Digital Elevation Models and Roadside Elements. Pro- 
cedia-Social and Behavioral Sciences, 160, 449-458.

https://doi.org/10.1016/j.sbspro.2014.12.157

[20] Castro, M., Iglesias, L., Rodríguez-Solano, R. and Sánchez, J.A. (2006) Geometric Modelling of Highways Using Global Positioning System (GPS) Data and Spline Approximation. Transportation Research Part C-Emerging Technologies, 14, 233-243. https://doi.org/10.1016/j.trc.2006.06.004

[21] Abdulhafedh, A. (2017) Identifying Vehicular Crash High Risk Locations along Highways via Spatial Autocorrelation Indices and Kernel Density Estimation. World Journal of Engineering and Technology, 5, 198-215.

https://doi.org/10.4236/wjet.2017.52016

[22] Cai, H. and Rasdorf, W. (2008) Modeling Road Centerlines and Predicting Lengths in 3-D Using LIDAR Point Cloud and Planimetric Road Centerline Data. Computer-Aided Civil and Infrastructure Engineering, 23, 157-173. https://doi.org/10.1111/j.1467-8667.2008.00518.x

[23] Abdulhafedh, A. (2016) Crash Frequency Analysis. Journal of Transportation Technologies, 6, 169-180. https://doi.org/10.4236/jtts.2016.64017

[24] Abdulhafedh, A. (2019) Design of Superelevation of Highway Curves: An Overview and Distribution Methods. Journal of City and Development, 1, 35-40.

[25] Imran, M., Hassan, Y. and Patterson, D. (2006) GPS-GIS-Based Procedure for Tracking Vehicle Path on Horizontal Alignments. Computer-Aided Civil and Infrastructure Engineering, 21, 383-394.

https://doi.org/10.1111/j.1467-8667.2006.00444.x 